Check for updates

Cite this: RSC Adv., 2017, 7, 20694

\title{
Fabrication of monodisperse nitrogen-doped carbon double-shell hollow nanoparticles for supercapacitors $\uparrow$
}

\author{
Juyoung Yun, Jaemoon Jun, Jungsup Lee, Jaehoon Ryu, Kisu Lee, Haejun Yu \\ and Jyongsik Jang (iD *
}

\begin{abstract}
Nitrogen-doped carbon double-shell nanoparticles (NC DS-HNPs) were fabricated using $\mathrm{SiO}_{2} / \mathrm{TiO}_{2}$ double-shell nanoparticles (ST DS-HNPs) and polydopamine-coating. The NC DS-HNPs have a high surface area of $873.52 \mathrm{~m}^{2} \mathrm{~g}^{-1}$ and a pore volume of $2.86 \mathrm{~cm}^{3} \mathrm{~g}^{-1}$, which are favorable characteristics for supercapacitors. In addition, nitrogen doping induced pseudo-capacitance via the redox activity of the surface functionalities. A specific capacitance of $202 \mathrm{~F} \mathrm{~g}^{-1}$ was achieved for supercapacitors based on NC DS-HNPs at a current density of $0.5 \mathrm{~A} \mathrm{~g}^{-1}$. Consequently, the unique morphology and electrochemical properties of NC DS-HNPs show great potential for future energy-related devices.
\end{abstract}

Received 15th March 2017

Accepted 31st March 2017

DOI: $10.1039 / \mathrm{c} 7 \mathrm{ra03077k}$

rsc.li/rsc-advances

Among carbon porous materials, hollow carbon nanoparticles

\section{Introduction}

Energy storage and conversion devices, including supercapacitors, solar cells, lithium-sulfur batteries, and fuel cells, have been developed due to increasing global pollution and energy resource shortages. ${ }^{1-9}$ Among them, supercapacitors, which can rapidly store excess electrical energy, have been implemented in many fields including portable electronics, automobile airbags, and power back-up systems. ${ }^{10}$ Supercapacitors have the advantages of high power density, short charging time, good stability, and ease of operation. ${ }^{\mathbf{1 1 , 1 2}}$ Their performance depends upon the physical and chemical properties of the electrode materials. Materials with large surface areas and high conductivities improve the electrochemical performance. ${ }^{5,13}$

Carbon-based materials such as graphene, ${ }^{5}$ carbon nanofibers, ${ }^{\mathbf{1 1}}$ carbon nanotubes, ${ }^{\mathbf{1 3}}$ carbon spheres, ${ }^{\mathbf{1 4}}$ and porous carbon $^{\mathbf{1 5 , 1 6}}$ have been studied as ecofriendly, low-cost materials for energy-related applications. Especially, nanoporous carbon materials offer large surface areas, unique structures, and high porosities, ${ }^{16,17}$ which have enhanced the performance of various devices, including supercapacitors, lithium-sulfur batteries, nanoreactors, and cathode materials for photovoltaics, as well as catalyst supports. ${ }^{18-22}$ The development of carbon nanostructures is a route to new solutions for these applications.

School of Chemical and Biological Engineering, Seoul National University, 599 Gwanangno, Gwanakgu, Seoul 151-742, Korea.E-mail: jsjang@plaza.snu.ac.kr; Fax: +82 2880 1604; Tel: +8228807069

$\dagger$ Electronic supplementary information (ESI) available: TEM images of STST CSNPs and ST DS-HNPs, STEM image of ST DS-HNPs, HR-TEM and TEM images of NC DS-HNPs, FE-SEM image of NC DS-HNPs, CV curve and charge-discharge curve of NC SS-HNPs and NC DS-HNPs. Contact angles. See DOI: $10.1039 / \mathrm{c} 7 \mathrm{ra} 03077 \mathrm{k}$ re of particular interest due to their low densities, unique morphologies, and pore size distributions. ${ }^{23}$ It is essential that the hollow carbon nanoparticles have well-defined, uniform structures. They are generally fabricated using a hard template method. ${ }^{24,25}$ The procedure involves coating a carbon precursor on a prepared solid core template, followed by carbonization and removal of the template. This method offers the advantage of uniform fabrication; however, it can be difficult to control the morphology. Moreover, the surface of the core solid template must be modified to ensure uniform carbon-source coating. ${ }^{16}$ The development of new nanostructures with high surface areas using simple methods remains challenging.

Herein, we suggest a new strategy to fabricate well-defined nitrogen-doped carbon double-shell nanoparticles (NC DSHNPs) to increase the surface area for the same particle size and improve the conductivity. The NC DS-HNPs were fabricated by polydopamine-coating of $\mathrm{SiO}_{2} / \mathrm{TiO}_{2}$ double-shell hollow nanoparticles (ST DS-HNPs), followed by carbonization and etching processes. In this double-shell structure, the robust nitrogen-doped carbon shells had higher surface areas and were nanoporous. Additionally, nitrogen doping enabled pseudo-capacitance by improving the charge mobility of the carbon shell. An NC DS-HNP-based supercapacitor exhibited a high specific capacitance of $202 \mathrm{~F} \mathrm{~g}^{-1}$, attributed to the larger surface area and nitrogen doping. To our knowledge, this is the first demonstration of an NC DS-HNP-based supercapacitor. The large surface area of $873.52 \mathrm{~m}^{2} \mathrm{~g}^{-1}$, pore volume of $2.86 \mathrm{~cm}^{3} \mathrm{~g}^{-1}$ and nitrogen doping in the NC DS-HNPs are favorable characteristics for supercapacitor electrode materials. 


\section{Results and discussion}

Fig. 1 shows a schematic diagram of nitrogen-doped carbon double-shell hollow nanoparticle (NC DS-HNP) fabrication. The NC DS-HNPs were synthesized via a template method with polydopamine (PD) coating. The $\mathrm{SiO}_{2} / \mathrm{TiO}_{2}$ double-shell hollow nanoparticles (ST DS-HNPs) that were used as templates were synthesized via a sonication-mediated etching process, as previously reported. ${ }^{26,27}$ First, the $\mathrm{SiO}_{2} / \mathrm{TiO}_{2}$ core/shell NPs (ST CSNPs) were created using a sol-gel method. Polyvinylpyrrolidone (PVP) was then added to the ST CSNPs to form $\mathrm{SiO}_{2}$ on the surface of $\mathrm{TiO}_{2}$. The carbonyl groups of the PVP interacted with the hydroxyl groups of the oxide surfaces. The PVP-treated ST CSNPs were coated with $\mathrm{SiO}_{2}$ shells via the Stöber method, which resulted in $\mathrm{SiO}_{2} / \mathrm{TiO}_{2} / \mathrm{SiO}_{2}$ core/shell nanoparticles (STS CSNPs). The $\mathrm{SiO}_{2} / \mathrm{TiO}_{2} / \mathrm{SiO}_{2} / \mathrm{TiO}_{2}$ core/shell nanoparticles (STST CSNPs) were fabricated by repeating the steps. Finally, STST CSNPs were etched with an $\mathrm{NH}_{4} \mathrm{OH}$ solution under sonication to obtain ST DS-HNPs. The etched silica and titania were released into the solution and diffused from inside to the titania shell. The silica and titania species were condensed and re-deposited on the titania shell due to Ostwald ripening. ${ }^{28}$ Fig. S1† exhibits TEM images of STST CSNPs, intermediate structured ST DS-HNP, and ST DS-HNPs as the etching proceeds. Fig. S2a $\dagger$ shows scanning transmission electron microscopy (STEM) images of ST DS-HNPs (average diameter: $220 \mathrm{~nm}$ ). Fig. S2b-d† display elemental dot mapping images of ST DS-HNPs. These images confirmed that the ST DSHNPs had inner and outer shells composed of silica and titania. The ST DS-HNPs used as templates were dispersed in deionized
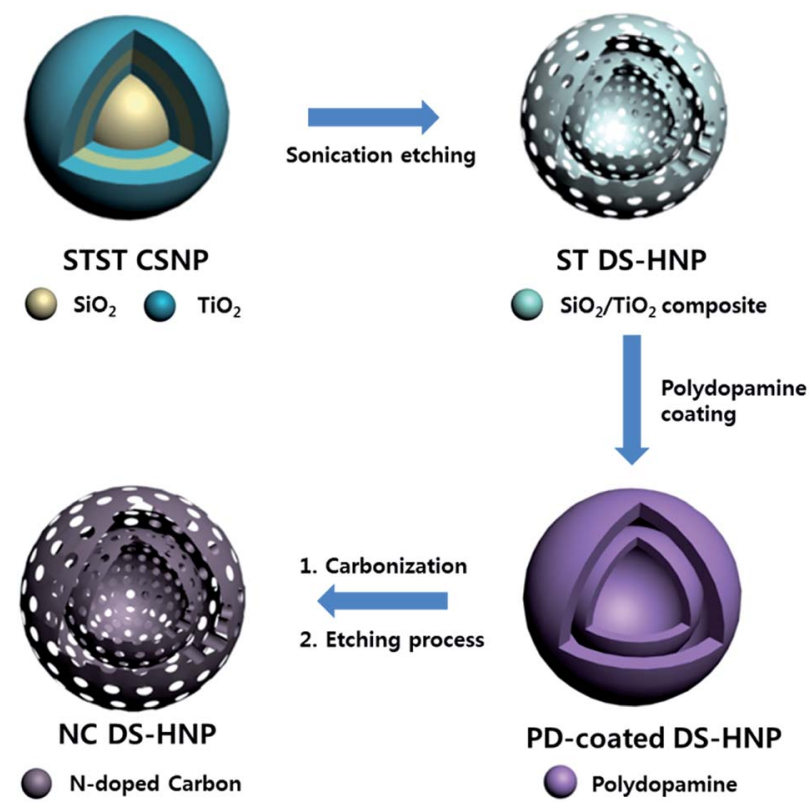

Fig. 1 Schematic illustration of NC DS-HNP synthesis. NC DS-HNPs: nitrogen-doped carbon double-shell hollow nanoparticles; STST CSNPS: $\mathrm{SiO}_{2} / \mathrm{TiO}_{2} / \mathrm{SiO}_{2} / \mathrm{TiO}_{2}$ core/shell nanoparticles; ST DSHNPs:SiO $2 / \mathrm{TiO}_{2}$ double-shell hollow nanoparticles; PD: polydopamine. water. Then, the carbon precursor was deposited onto the inner and outer shells of the ST DS-HNPs template by PD pyrolysis. After carbonization of $\mathrm{PD}$ at $800{ }^{\circ} \mathrm{C}$, the templates were removed with dilute HF solution, leaving NC DS-HNPs.

Fig. 2a and b show TEM images of $\mathrm{SiO}_{2} / \mathrm{TiO}_{2}$ single-shell hollow nanoparticles (ST SS-HNP) and ST DS-HNPs templates; the average particle size was $220 \mathrm{~nm}$. Carbonization and etching processes formed the nitrogen-doped carbon single-shell nanoparticles (NC SS-HNPs) and NC DS-HNPs. The NC SSHNPs of the same size as the NC DS-HNPs were used as a control to evaluate the effect of the number of shells. Fig. 2c and d show TEM images of the NC SS-HNPs and NC DS-HNPs with an average diameter of $220 \mathrm{~nm}$. Unlike the ST DS-HNPs, the inner shell of the NC DS-HNPs was not always located in the center of the NC DS-HNPs. It was usually moved to within the outer shell after elimination of the $\mathrm{SiO}_{2} / \mathrm{TiO}_{2}$ template. The TEM and FE-SEM images of a collection of NC DS-HNPs in Fig. S3a and $\mathrm{S} 4 \dagger$ confirmed the uniformity of the fabricated NC DS-HNPs.

Scanning transmission electron microscopy-energy dispersive spectroscopy (STEM-EDS) was used to investigate the elemental distribution in the NC DS-HNPs; the elemental dot maps and line analyses are shown in Fig. 3. Fig. 3a and S3b $\dagger$ show STEM and high-resolution TEM (HR-TEM) images of the NC DS-HNPs, revealing inner and outer shells with average diameters of 120 and $220 \mathrm{~nm}$, respectively. The thicknesses of the inner and outer shells were about 20 and $30 \mathrm{~nm}$, respectively. Fig. 3b-d display elemental dot maps of the NC DS-HNPs. In Fig. 3b, the overlapping elemental dot maps of the NC DSHNPs are seen as red dots on the green shells, demonstrating that the well-defined DS-HNPs consisted of a relatively large amount of carbon and a small amount of nitrogen. Fig. $3 \mathrm{c}$ and
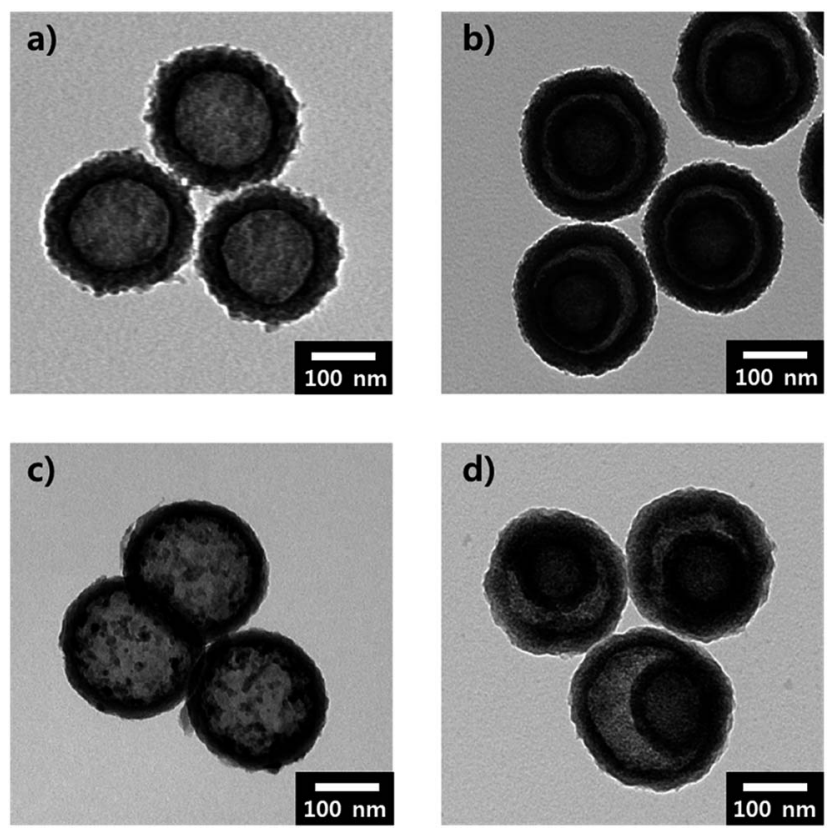

Fig. 2 Transmission electron microscopy (TEM) images of (a) ST SSHNPs, (b) ST DS-HNPs, (c) NC SS-HNPs, and (d) NC DS-HNPs. 

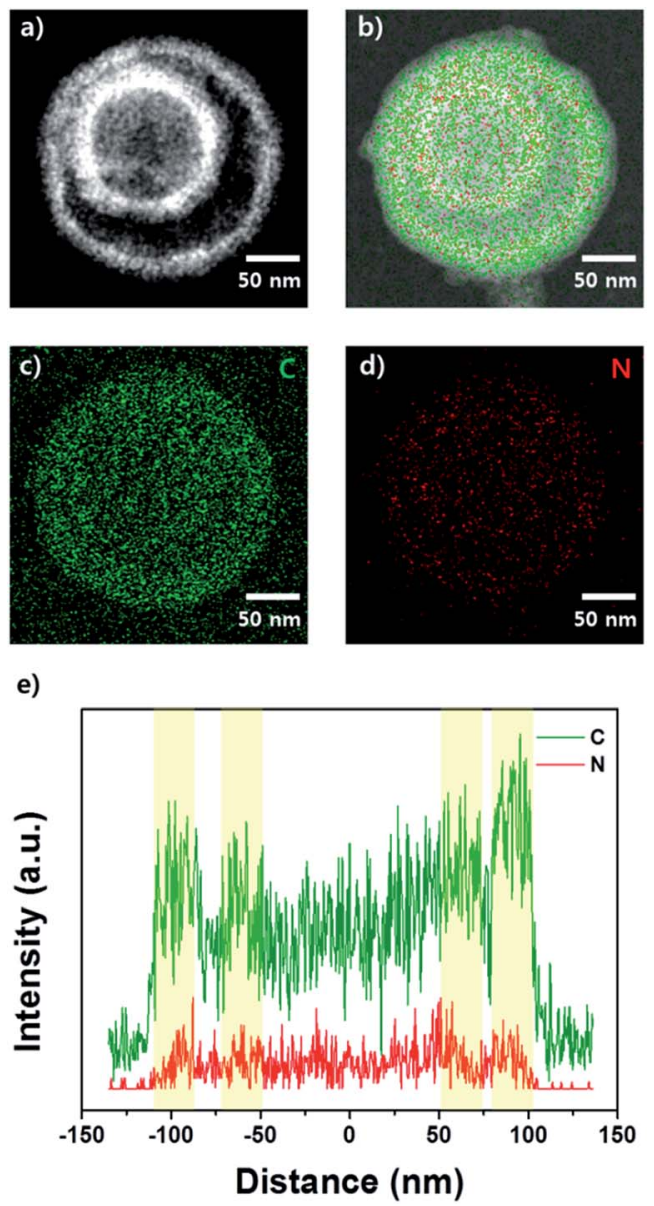

Fig. 3 (a) Scanning transmission electron microscopy (STEM) image of NC DS-HNPs and the corresponding (b) overlapped elemental dot maps, (c) carbon map and (d) nitrogen map. (e) STEM-energy dispersive spectroscopy (STEM-EDS) line maps of NC DS-HNPs. The green color represents carbon; the red color indicates nitrogen.

d show the carbon and nitrogen dot maps, respectively. The STEM-EDS line analysis shown in Fig. 3e indicates that the NC DS-HNPs had inner and outer shells containing carbon and nitrogen, and that the elements were uniformly distributed. The atomic ratio of carbon to nitrogen was 0.05 according to STEMEDS analyses, which indicated that nitrogen was doped in the carbon shells.

The Brunauer-Emmett-Teller (BET) analyses of the NC SS, DS-HNPs and their equivalent Barrett-Joyner-Halenda (BJH) pore size distributions were used to evaluate the pore characteristics. Fig. 4a and b provide BET analyses of the NC SS-HNPs and NC DS-HNPs, respectively. Both had type-IV isotherms that indicated mesoporous characteristics and a large specific surface area. ${ }^{29}$ Because the templates had mesoporous characteristics, nanopores in the nitrogen-doped carbon shell were generated during carbonization. From the pore characteristics in Table S1, $\uparrow$ the BET surface areas of the NC DS-HNPs and NC SS-HNPs were 873.52 and $511.21 \mathrm{~m}^{2} \mathrm{~g}^{-1}$, and pore volume were 2.86 and $0.88 \mathrm{~cm}^{3} \mathrm{~g}^{-1}$, respectively. This demonstrated that the inner shell of the NC DS-HNPs increased the BET surface area and pore volume. Fig. $4 \mathrm{c}$ and $\mathrm{d}$ exhibit the $\mathrm{BJH}$ pore size
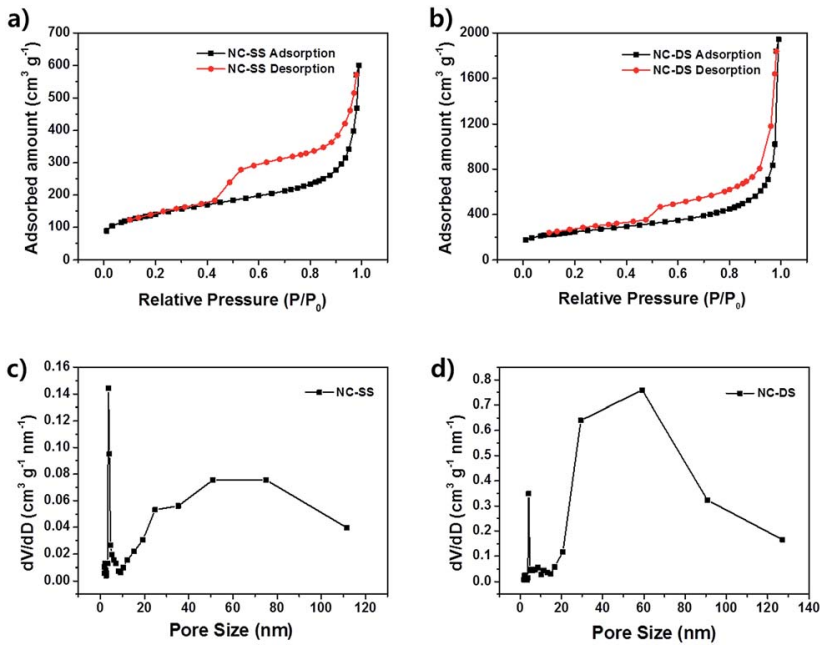

Fig. 4 Brunauer-Emmett-Teller (BET) analyses of (a) NC SS-HNPs and (b) NC DS-HNPs. Barrett-Joyner-Halenda (BJH) pore size distributions of (c) NC SS-HNPs and (d) NC DS-HNPs.

distributions of the NC SS-HNPs and NC DS-HNPs, respectively. Both consisted of small $(4.1 \pm 0.5 \mathrm{~nm})$ and large $(\geq 20 \mathrm{~nm})$ pores within the intrashell and inner cavities. The data indicate that the NC DS-HNPs had more small and large pores compared with the NC SS-HNPs, which resulted in a higher surface area and pore volume. The amount of large pores in the NC DS-HNPs was greater because the presence of the inner shell provided more pores. The pores between the inner and outer shells and the inside pores of the inner shell increased the number of large pores.

X-ray photoelectron spectroscopy (XPS) was used to investigate the elemental chemical states and contents of the NC DSHNPs. Fig. 5a shows the survey spectra of the NC DS-HNPs, revealing the presence of $\mathrm{C}, \mathrm{O}$, and $\mathrm{N}$. The carbon content in the NC DS-HNPs dominated; the atomic nitrogen concentration was $4.62 \%$. This result was in good agreement with STEM-EDS observations. The presence of the $\mathrm{O} 1 \mathrm{~s}$ peak in the survey spectrum of the NC DS-HNPs was attributed to partial surface oxidation. ${ }^{1,30}$ Fig. 5b displays the high-resolution $\mathrm{C} 1 \mathrm{~s}$ peak, which was deconvoluted into four components. The peaks at 284.5, 285.3, 285.27, and $288.61 \mathrm{eV}$ were assigned to $\mathrm{C}=\mathrm{C}, \mathrm{C}-\mathrm{C}$, $\mathrm{C}-\mathrm{O}$ and $\mathrm{C}=\mathrm{N}$, and $\mathrm{C}-\mathrm{O}-\mathrm{C}$ and $\mathrm{C}-\mathrm{N}$ functional groups, respectively. ${ }^{30,31}$ The $\mathrm{C}=\mathrm{C}$ configuration was the main $\mathrm{C} 1 \mathrm{~s}$ peak, and was responsible for the good electrical properties. The nitrogen-doped carbon structure also improved the electrochemical properties. ${ }^{32}$ The high-resolution $\mathrm{N}$ 1s peak was deconvoluted into the following four components: pyridinic $\mathrm{N}$ (398.22), pyrrolic or pyridonic $\mathrm{N}$ (399.47), quaternary $\mathrm{N}$ (400.74), and oxidized $\mathrm{N}(402.02 \mathrm{eV})$ as shown in Fig. $5 \mathrm{c}^{33,34}$ The pyridinic and quaternary nitrogens comprised large portions of the $\mathrm{N} 1 \mathrm{~s}$ peak; these groups are more electrocatalytically active than the others. ${ }^{35}$ The pyridinic $\mathrm{N}$ atoms were located at the edge of the carbon plane, and the quaternary $\mathrm{N}$ atoms were bonded to three carbon atoms within the carbon plane. The nitrogen functional groups provide chemically active sites to improve the electrochemical properties of supercapacitors. Hence, carbonization of 

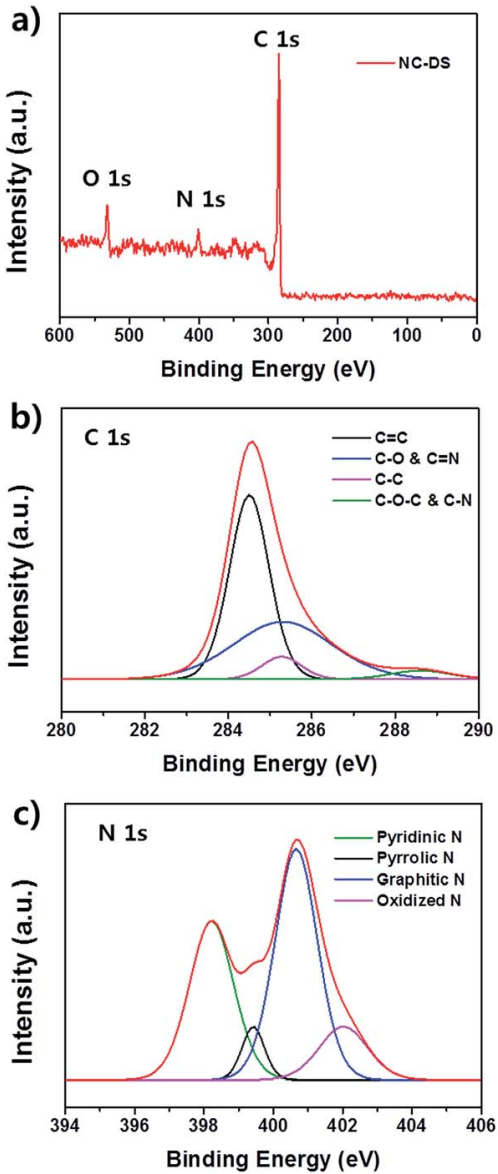

Fig. 5 (a) X-ray photoelectron spectra (XPS) of the NC DS-HNPs and the corresponding high-resolution XPS spectra of (b) $C$ 1s and (c) N 1s features.

PD would be a good approach to introduce chemically active sites into carbon materials.

To further investigate properties of NC DS-HNPs, the electrochemical performance of the NC DS-HNPs was measured by cyclic voltammetry and galvanostatic charge-discharge tests in a three-electrode cell in $1 \mathrm{M} \mathrm{H}_{2} \mathrm{SO}_{4}$ solution. Fig. S5a $\uparrow$ compares the cyclic voltammetry (CV) curve of NC SS-HNPs and NC DSHNPs based supercapacitors at $20 \mathrm{mV} \mathrm{s}^{-1}$. Both curve exhibit quasi-rectangular shapes with pseudo capacitance behavior. The NC DS-HNPs based supercapacitor has a larger curve, indicating a higher capacitance due to high surface area and pore volume. The galvanostatic charge-discharge curve also reflects higher capacitance of the NC DS-HNPs based supercapacitor than the NC SS-HNPs (Fig. S5b†). The pseudocapacitive behavior over a wide voltage was attributed to a faradaic redox reaction of the nitrogen dopants. ${ }^{41}$ Nitrogen doping in carbon materials improve supercapacitive performance via participation in a pseudo-capacitance reaction enabled by enhanced electrolyte wettability and electrical conductivity. ${ }^{42,43}$ To investigate electrolyte wettability of nitrogen doped carbon, the water contact angle of carbon based films were measured (Fig. S6†). The control of NC DS-HNPs film was carbon black film which had no heteroatom. The contact angle of NC DS-
HNPs film was smaller than that of carbon black film. This result indicated the nitrogen doping increased the electrolyte wettability. Furthermore, the porous nanostructures and high surface area of the hollow structure also enhances supercapacitive performance. The nanopores in the nitrogen-doped carbon double-shell allow greater absorption of electrolyte ions, increasing the capacitance. Fig. 6a show CV curves of NC DS-HNPs based supercapacitor with different scan rates. The CV curves retained quasi-rectangular shape from 5 to $100 \mathrm{mV} \mathrm{s}^{-1}$, revealing good rate electrochemical performance. Fig. $6 \mathrm{~b}$ shows the galvanostatic charge-discharge curves of the NC DS-HNPs; the nonlinearity indicates pseudo-capacitive behavior. ${ }^{1}$ The specific capacitance approached $202 \mathrm{~F} \mathrm{~g}^{-1}$ at a current density of $0.5 \mathrm{~A} \mathrm{~g}^{-1}$, and the capacitance retention was $75 \%$ in $1 \mathrm{M}$ $\mathrm{H}_{2} \mathrm{SO}_{4}$ solution at a current density ranging from 0.5 to $10 \mathrm{Ag}^{-1}$. Excellent retention is important for applications with a high discharge-recharge rate. Table 1 displays the capacitance of $\mathrm{N}$ doped carbon materials reported in literatures. The NC DSHNPs based supercapacitor had relatively high capacitance. Fig. 6c shows the electrochemical impedance spectroscopy (EIS) results over a frequency ranging from $0.01 \mathrm{~Hz}$ to $0.1 \mathrm{MHz}$; the inset shows the high-frequency data. The Nyquist plot was semicircular at high frequencies and a straight line at low frequencies. The intercept at the start of the semicircle and the size of the semicircle correspond to the series resistance and the charge transfer resistance at the interface between the electrode and electrolyte, which were 1.1 and $1.45 \Omega$, respectively. The small resistances indicated favorable charge-transfer kinetics for the NC DS-HNPs electrode. Fig. 6d indicates that NC SSHNPs and NC DS-HNPs based electrodes were electrochemically stable with only $9 \%$ and $7 \%$ loss in specific capacitance after 5000 cycles at a current density of $1 \mathrm{~A} \mathrm{~g}^{-1}$, respectively. The NC DS-HNPs based electrode was more stable than the NC SSHNPs based one. The excellent capacitance retention indicated a robust structure over the charge-discharge process.
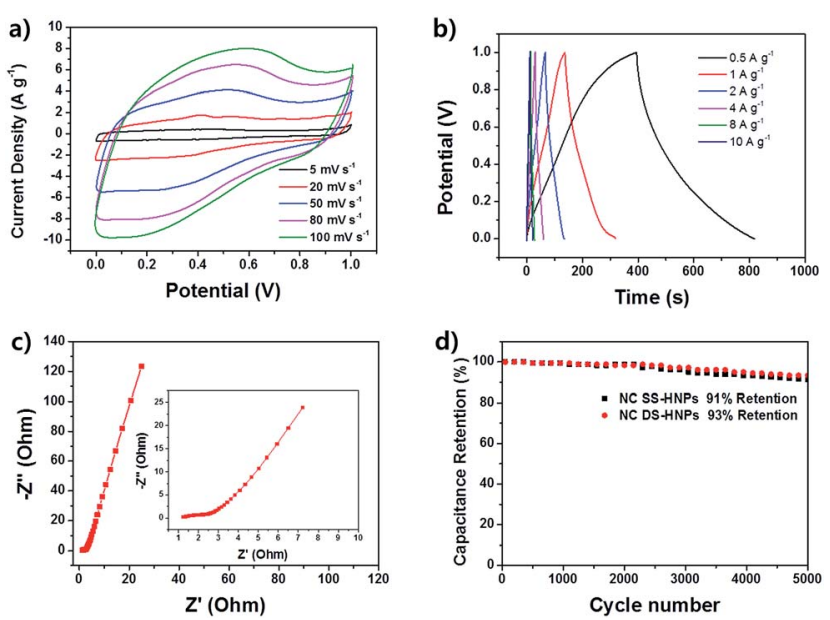

Fig. 6 (a) Cyclic voltammograms of the NC DS-HNPs at various scan rates, (b) charge-discharge curves of the NC DS-HNPs, (c) electrochemical impedance spectra (EIS) of the NC DS-HNPs (inset: magnified region), and (d) cycling performance of the NC SS-HNPs and NC DS-HNPs at a current density of $1 \mathrm{~A} \mathrm{~g}^{-1}$. 
Table 1 Capacitances of $\mathrm{N}$-doped carbon materials from the literature

\begin{tabular}{llcc}
\hline Sample & Capacitance $\left(\mathrm{F} \mathrm{g}^{-1}\right)$ & Current density $\left(\mathrm{A} \mathrm{g}^{-1}\right)$ & Electrolyte \\
\hline $\begin{array}{l}\text { Porous N-doped hollow carbon } \\
\text { Sphere }\end{array}$ & 176 & 1 & $6 \mathrm{M} \mathrm{KOH}$ \\
N-doped mesoporous carbon & 180 & 1 & 36 \\
N-doped porous carbon & 210 & 1 & $1 \mathrm{M} \mathrm{H}_{2} \mathrm{SO}_{4}$ \\
Mesoporous N-doped carbons & 182 & 1 & $6 \mathrm{M} \mathrm{KOH}$ \\
N-doped hollow carbon sphere & 170 & 1 & $6 \mathrm{M} \mathrm{KOH}$ \\
NC DS-HNPs & 184 & 1 & $6 \mathrm{M} \mathrm{KOH}$ \\
\end{tabular}

Fig. S7 $\uparrow$ shows the robust structure of NC DS-HNPs after 5000 cycles at a current density of $1 \mathrm{~A} \mathrm{~g}^{-1}$. The NC DS-HNPs had a unique structure and composition, which led to high specific capacitance, outstanding stability, and remarkable capacitance retention.

\section{Conclusions}

Summarizing, we successfully designed uniquely structured NC DS-HNPs using a straightforward approach. These nanoparticles were fabricated via polymerization of dopamine onto ST DS-HNPs, followed by carbonization and etching. The morphology of the nitrogen-doped carbon was decided by controlling the number of template shells. The incorporation of nitrogen led to increased electrolyte wettability, good electrical conductivity and pseudo-capacitance. The high surface area of the NC DS-HNPs resulted in a high specific capacitance of $202 \mathrm{~F}$ $\mathrm{g}^{-1}$ at current density of $0.5 \mathrm{~A} \mathrm{~g}^{-1}$. The robust structure of an NC DS-HNPs electrode enabled good cyclic stability ( $93 \%$ capacitance retention after 5000 cycles). This technique of fabricating well-defined carbon hollow structures will assist in the development of other novel porous materials.

\section{Experimental section}

\section{Fabrication of NC DS-HNPs}

The $\mathrm{SiO}_{2} / \mathrm{TiO}_{2}$ double-shell nanoparticles (ST DS-HNPs) template was prepared as reported previously. ${ }^{26,27}$ The ST DSHNPs $(200 \mathrm{mg})$ were dispersed in $300 \mathrm{~mL}$ of $\mathrm{H}_{2} \mathrm{O}$ using sonication. Dopamine $(180 \mathrm{mg})$ and Tris $(100 \mathrm{mg})$ were added to the prepared solution and stirred for $24 \mathrm{~h}$. The polydopamine (PD)coated template was collected by centrifugation. The PD-coated ST DS-HNPs were then heated under a flow of argon gas at $800{ }^{\circ} \mathrm{C}$ for $2 \mathrm{~h}$ to carbonize PD. The template was removed by dilute HF acid solution over $6 \mathrm{~h}$ to yield nitrogen-doped carbon double-shell nanoparticles (NC DS-HNPs). Following etching, the final products were isolated by centrifugation and then washed and dried in a vacuum oven.

\section{Electrochemical measurements}

A NC DS-HNP-based electrode for a supercapacitor was prepared as follows. A mixture of $0.05 \mathrm{~g}$ of the NC DS-HNPs and $0.5 \mathrm{mg}$ of poly(vinylidene fluoride) (PVDF) as a binder were dissolved in $N$-methyl-pyrrolidone to form a paste. Then, the paste was applied to a stainless steel mesh (area: $0.5 \mathrm{~cm}^{2}$ ) and dried for $12 \mathrm{~h}$ at $25{ }^{\circ} \mathrm{C}$ in a vacuum oven. The electrochemical properties of the NC DS-HNPs were measured using a threeelectrode system composed of $1 \mathrm{M} \mathrm{H}_{2} \mathrm{SO}_{4}$, an $\mathrm{Ag} / \mathrm{AgCl}$ reference electrode and a Pt electrode. Cyclic voltammograms were obtained over a voltage range of 0 to $1.0 \mathrm{~V}$ at various scan rates $\left(5-200 \mathrm{mV} \mathrm{s}^{-1}\right)$. Galvanostatic charge-discharge analyses were carried out over the range of 0 to $1.0 \mathrm{~V}$ at various current densities $\left(0.5-10 \mathrm{~A} \mathrm{~g}^{-1}\right)$. The galvanostatic charge-discharge test at a current density of $1 \mathrm{~A} \mathrm{~g}^{-1}$ over 5000 cycles was used as an indication of the stability. Electrochemical impedance spectroscopy (EIS) spectra were recorded from $0.01 \mathrm{~Hz}$ to 0.1 MHz using a Zahmer Elektrik IM6 analyzer.

\section{Characterization}

Transmission electron microscopy (TEM) and field-effect scanning electron microscopy (FE-SEM) images were obtained using JEOL JEM-200CX and JEOL JSM6700-F instruments. The electron energy loss spectroscopy mapping and scanning transmission electron microscopy-energy dispersive spectroscopy (STEM-EDS) line analyses were performed using a JEOL JEM$2100 \mathrm{~F}$ instrument. X-ray photoelectron spectroscopy (XPS) measurements were carried out with an AXIS-his instrument. The Brunauer-Emmett-Teller (BET) surface area measurements and Barrett-Joyner-Halenda (BJH) pore-size distributions were obtained using an ASAP 2010 instrument. Water contact angle measurement was performed by an SDLab-200TEZD goniometer (Femtofab, Korea).

Supplementary calculations: the specific capacitance $\left(C_{\mathrm{s}}\right)$ of a working electrode is defined as the capacitance per unit mass of one electrode. The specific capacitance is given by

$$
C_{\mathrm{s}}=\frac{C_{\text {electrode }}}{m}
$$

where $C_{\text {electrode }}$ is the capacitance of the electrode materials in the three-electrode cell system and $m$ is the mass of the materials in the active area. For galvanostatic charge-discharge measurements, the specific capacitance is determined as follows:

$$
C_{\mathrm{s}}=\frac{I \times \Delta t}{\Delta V \times m},
$$

where $I$ is the discharge current, $\Delta V$ is the voltage difference of the discharge, and $\Delta t$ is the discharge time. 


\section{Acknowledgements}

This work was supported by Global Frontier R\&D Program of the Center for Multiscale Energy System funded by the National Research Foundation under the Ministry of Education, Science and Technology, Korea (2011-0031573).

\section{Notes and references}

1 J. Zhou, J. Lian, L. Hou, J. Zhang, H. Gou, M. Xia, Y. Zhao, T. A. Strobel, L. Tao and F. Gao, Nat. Commun., 2015, 6, 8503.

2 L. Li, A.-R. O. Raji and J. M. Tour, Adv. Mater., 2013, 25, 6298-6302.

3 X.-Y. Shan, Y. Wang, D.-W. Wang, F. Li and H.-M. Cheng, Adv. Energy Mater., 2016, 6, 1502064.

4 H. Ji, X. Zhao, Z. Qiao, J. Jung, Y. Zhu, Y. Lu, L. L. Zhang, A. H. MacDonald and R. S. Ruoff, Nat. Commun., 2014, 5, 3317.

5 Y. Xu, Z. Lin, X. Zhong, X. Huang, N. O. Weiss, Y. Huang and X. Duan, Nat. Commun., 2014, 5, 4554.

6 J. Yun, J. Ryu, J. Lee, H. Yu and J. Jang, J. Mater. Chem. A, 2016, 4, 1306.

7 W. Zhou, X. Xiao, M. Cai and L. Yang, Nano Lett., 2014, 14, 5250 .

8 Z. Wen, Q. Wang, Q. Zhang and J. Li, Electrochem. Commun., 2007, 9, 1867.

9 J. Noh, C. M. Yoon, Y. K. Kim and J. Jang, Carbon, 2017, 116, 470.

10 B. G. Choi, M. Yang, W. H. Hong, J. W. Choi and Y. S. Huh, ACS Nano, 2012, 6, 4020.

11 J. Jun, J. S. Lee, D. H. Shin, S. G. Kim and J. Jang, Nanoscale, 2015, 7, 16026.

12 H.-Y. Wang, F.-X. Xiao, L. Yu, B. Liu and X. W. Lou, Small, 2014, 10, 3181.

13 C. Choi, J. A. Lee, A. Y. Choi, Y. T. Kim, X. Lepró, M. D. Lima, R. H. Baughman and S. J. Kim, Adv. Mater., 2014, 26, 2059.

14 M. Liu, J. Qian, Y. Zhao, D. Zhu, L. Gan and L. Chen, J. Mater. Chem. A, 2015, 3, 11517.

15 J. Lee, J. Kim and T. Hyeon, Adv. Mater., 2006, 18, 2073.

16 F. Xu, Z. Tang, S. Huang, L. Chen, Y. Liang, W. Mai, H. Zhong, R. Fu and D. Wu, Nat. Commun., 2015, 6, 7221.

17 A. Stein, Z. Wang and M. A. Fierke, Adv. Mater., 2009, 21, 265.

18 R. Liu, S. M. Mahurin, C. Li, R. R. Unocic, J. C. Idrobo, H. Gao, S. J. Pennycook and S. Dai, Angew. Chem., Int. Ed., 2011, 50, 6799.

19 G. Zheng, S. W. Lee, Z. Liang, H.-W. Lee, K. Yan, H. Yao, H. Wang, W. Li, S. Chu and Y. Cui, Nat. Nanotechnol., 2014, 9, 618.
20 S. L. Candelaria, Y. Shao, W. Zhou, X. Li, J. Xiao, J.-G. Zhang, Y. Wang, J. Liu, J. Li and G. Cao, Nano Energy, 2012, 1, 195.

21 S. B. Yoon, K. Sohn, J. Y. Kim, C. H. Shin, J. S. Yu and T. Hyeon, Adv. Mater., 2002, 14, 19.

22 J.-S. Yu, S. Kang, S. B. Yoon and G. Chai, J. Am. Chem. Soc., 2002, 124, 9382.

23 S. Yang, X. Feng, L. Zhi, Q. Cao, J. Maier and K. Müllen, Adv. Mater., 2010, 22, 838.

24 R. J. White, K. Tauer, M. Antonietti and M.-M. Titirici, J. Am. Chem. Soc., 2010, 132, 17360.

25 A.-H. Lu, T. Sun, W.-C. Li, Q. Sun, F. Han, D.-H. Liu and Y. Guo, Angew. Chem., Int. Ed., 2011, 50, 11765.

26 J. Lee, S. H. Hwang, J. Yun and J. Jang, ACS Appl. Mater. Interfaces, 2014, 6, 15420.

27 S. Lee, J. Lee, S. H. Hwang, J. Yun and J. Jang, ACS Nano, 2015, 9, 4939.

28 M. Choi, C. Kim, S. Ok Jeon, K. Soo Yook, J. Yeob Lee and J. Jang, Chem. Commun., 2011, 47, 7092.

29 J. Yun, S. H. Hwang and J. Jang, ACS Appl. Mater. Interfaces, 2015, 7, 2055.

30 D. Hulicova-Jurcakova, M. Seredych, G. Q. Lu and T. J. Bandosz, Adv. Funct. Mater., 2009, 19, 438.

31 Z.-H. Sheng, L. Shao, J.-J. Chen, W.-J. Bao, F.-B. Wang and X.-H. Xia, ACS Nano, 2011, 5, 4350.

32 D. Zhou, L. Yang, L. Yu, J. Kong, X. Yao, W. Liu, Z. Xu and X. Lu, Nanoscale, 2015, 7, 1501.

33 S. Chen, J. Bi, Y. Zhao, L. Yang, C. Zhang, Y. Ma, Q. Wu, X. Wang and Z. Hu, Adv. Mater., 2012, 24, 5593.

34 T. Sharifi, G. Hu, X. Jia and T. Wågberg, ACS Nano, 2012, 6, 8904.

35 T. Xing, Y. Zheng, L. H. Li, B. C. C. Cowie, D. Gunzelmann, S. Z. Qiao, S. Huang and Y. Chen, ACS Nano, 2014, 8, 6856.

36 J. Han, G. Xu, B. Ding, J. Pan, H. Dou and D. R. MacFarlane, J. Mater. Chem. A, 2014, 2, 5352.

37 G. A. Ferrero, M. Sevilla and A. B. Fuertes, Carbon, 2015, 88, 239.

38 B. Qiu, C. Pan, W. Qian, Y. Peng, L. Qiu and F. Yan, J. Mater. Chem. A, 2013, 1, 6373.

39 L. Zhao, L.-Z. Fan, M.-Q. Zhou, H. Guan, S. Qiao, M. Antonietti and M.-M. Titirici, Adv. Mater., 2010, 22, 5202. 40 A. Chen, Y. Li, Y. Yu, S. Ren, Y. Wang, K. Xia and S. Li, J. Alloys Compd., 2016, 688, 878.

41 P. Simon, Y. Gogotsi and B. Dunn, Science, 2014, 343, 1210. 42 D. S. Su and R. Schlögl, ChemSusChem, 2010, 3, 136.

43 F. Su, C. K. Poh, J. S. Chen, G. Xu, D. Wang, Q. Li, J. Lin and X. W. Lou, Energy Environ. Sci., 2011, 4, 717. 